\title{
Small Intestine Strangulating Obstruction by Mesenteric Pedunculated Lipoma in a Criollo Mare
}

\author{
Rafaela Pinto de Souza, Leandro Américo Rafael, Mariana Andrade Mousquer, \\ Vitória Müller, Plínio Amélio Ocanha Ávila, Débora Machado Nogueira, \\ Bruna da Rosa Curcio \& Carlos Eduardo Wayne Nogueira
}

\begin{abstract}
Background: The abdominal lipomas are benign tumors of hyperplastic growth that originate from mesenteric adipose tissue, most commonly in the small intestine. Pedunculated lipoma strangulation occurs when the pedicle wraps around an intestinal loop and its mesentery, obstructing the intestinal lumen and blood supply of the affected segment. The aim of the present study is to report a case of a Criollo mare presenting a strangulating obstruction of the jejunum and ileum by a pedunculated lipoma, focusing the discussion in the causes and epidemiology of this alteration.

Case: A 24-year-old Criollo mare with a body condition score 8 out of 9 was referred to the Veterinary Clinical Hospital of the Federal University of Pelotas (HCV-UFPel) presenting acute abdominal pain. At the hospital, the mare was presenting mild signs of abdominal discomfort. At the initial clinical exam, the mare had an increased heart and respiratory rates, normal body temperature, hyperemic mucous membranes, capillary refil time of $3 \mathrm{~s}$ and absent gut sounds in all four quadrants during auscultation. Mild dehydration was present, increased fibrinogen and serum lactate. Rectal palpation revealed distention of the small intestine by gas, during abdominal ultrassonography the small intestinal wall thickness was increased Peritoneal lactate was $11 \mathrm{mmol} / \mathrm{L}$ and protein was $6 \mathrm{mg} / \mathrm{dL}$. Due to the clinical findings during the exam, an exploratory celiotomy was performed. Necrosis of the final third of jejunum and the entire extension of ileum was found. Examining the compromised intestinal portion, it was observed a linear structure strangulating two segments of the small intestine. Taking into account the extensive area of irreversible necrosis and the advanced age of the patient, euthanasia was performed. The mare was then referred for necropsy and findings confirmed the strangulation of the final portion of the jejunum and all the extension of the ileum caused by a mesenteric pedunculated lipoma.

Discussion: Increased mesenteric fat can predispose horses to the development of mesenteric lipomas. Although there is no scientific evidence of the association of mesenteric lipoma and obesity, it has been observed that pedunculated lipomas are more common in horses with metabolic alterations, for example, Criollo breed, that is potentially predisposed to develop metabolic disturbances. Elderly horses are at the highest risk of colic by mesenteric lipoma, as well as geldings, however, other authors describe that females are more commonly affected. Horses considered of short stature are more predisposed when compared to jumping or race horses. Pedunculated lipoma occurs in 18\% of all cases of treated colic and is found more frequently in the small intestine when compared to the small colon. In most cases, surgery is indicated and resection of the pedicle and the affected segment may be necessary, however, in this case, the extensive area of intestinal necrosis and the impossibility of externalization of the affected segment lead the decision to proceed with euthanasia. In conclusion, the mare of the present study had an advanced age and a high body condition score, which the authors' believe were two predisposing factors that increased the risk of it developing a mesenteric lipoma. Considering that, further epidemiologic studies should be conducted to better understand this relation.
\end{abstract}

Keywords: mesenteric lipoma, obesity, Criollo mare, metabolic disturbances.

DOI: $10.22456 / 1679-9216.99983$ 


\section{INTRODUCTION}

Strangulating obstructions of the small intestine are characterized by simultaneous occlusion of the intestinal lumen and its blood supply, accounting for $27 \%$ to $49 \%$ of the cases of surgical colic $[1,12]$. Abdominal lipomas are benign tumors of hyperplastic growth that originate from mesenteric adipose tissue, most commonly in the small intestine. It may be present as a solitary tumor or multiple, broad-based or pedunculated, occurring more frequently in elderly horses [1,9]. Geldings and ponies are more likely to develop this condition $[5,9]$.

Strangulation by pedunculated lipoma occurs when the pedicle wraps around an intestinal loop and its mesentery, obstructing the intestinal lumen and blood supply of the affected segment. The treatment requires resection of the lipoma at the base of the pedicle and the compromised intestinal portion, followed by enteroanastomosis $[1,5,9]$.

There are several reports showing lipomas as emergency cases discussing surgical techniques and clinical outcome, however, little epidemiological focus has been given to the disease and, to the author's knowledge, no reports of the disease occurring in Criollo horses has been published. Therefore, the aim of this study is to report a case of a Criollo mare presenting a strangulating obstruction of the jejunum and ileum by a pedunculated lipoma, focusing in the causes and epidemiology of this alteration.

\section{CASE}

A 24-year-old Criollo mare, weighing $460 \mathrm{~kg}$ with a body condition score (BCS) 8 out of 9 [10] was referred to the Veterinary Clinical Hospital of the Federal University of Pelotas (HCV-UFPel) presenting acute abdominal pain. The owner reported that the mare was maintained exclusively in a pasture and started presenting signs of colic $12 \mathrm{~h}$ before the referral. It was treated initially by the referring veterinary at the property.

When the mare arrived at the hospital, it was lethargic and presenting mild signs of abdominal discomfort. At the initial clinical exam the heart rate (HR) was $68 \mathrm{bpm}$, respiratory rate (RR) was $44 \mathrm{bpm}$, body temperature $37.8^{\circ} \mathrm{C}$, hyperemic mucous membranes with a capillary refil time (CRT) of $3 \mathrm{~s}$ and borborygmi was absent in all four quadrants. Packed cell volume (PCV) was $40 \%$, total plasma protein (TPP) was
$8.6 \mathrm{~g} / \mathrm{dL}$, fibrinogen $600 \mathrm{mg} / \mathrm{dL}$ and serum lactate $5.2 \mathrm{mmol} / \mathrm{L}$. Nasogastric intubation was performed but no reflux was obtained. Rectal palpation revealed distention of the small intestine by gas, abdominal ultrassonography evaluation confirmed the distention, the small intestinal wall thickness was increased $(1.9 \mathrm{~cm})$. Gross visual evaluation of peritoneal fluid showed increased turbidity and had a reddish color. Peritoneal lactate was $11 \mathrm{mmol} / \mathrm{L}$ and protein was $6 \mathrm{mg} / \mathrm{dL}$.

Due to the clinical findings during the exam, an exploratory celiotomy was performed. Benzylpenicillin benzathine (Agrosil PPU ${ }^{1}, 20,000 \mathrm{UI} / \mathrm{kg}, \mathrm{IM}$ ) and Gentamycin (Pangram ${ }^{2}, 6.6 \mathrm{mg} / \mathrm{kg}$, IV) were administered as prophylactic antibiotic therapy and flunixin meglumine (Flumedin ${ }^{3}, 1.1 \mathrm{mg} / \mathrm{kg}$, IV) was used as anti-inflamatory and analgesic.

During surgery, necrosis of the final third of jejunum and the entire extension of ileum was found. Examining the compromised intestinal portion, it was observed a linear structure strangulating two segments of the small intestine. Exteriorization of this segment was not possible. Taking into account the extensive area of irreversible necrosis and the advanced age of the patient, euthanasia was performed. The mare was then referred to the Regional laboratory of diagnosis of the Federal University of Pelotas for necropsy. Necropsy findings confirmed the strangulation of the final portion of the jejunum and all the extension of the ileum caused by a lipoma of approximately $5 \mathrm{~cm}$ in diameter attached to a peduncle (Figure $1 \&$ Figure 2).

\section{DISCUSSION}

Increased mesenteric fat can predispose horses to the development of mesenteric lipomas [14].

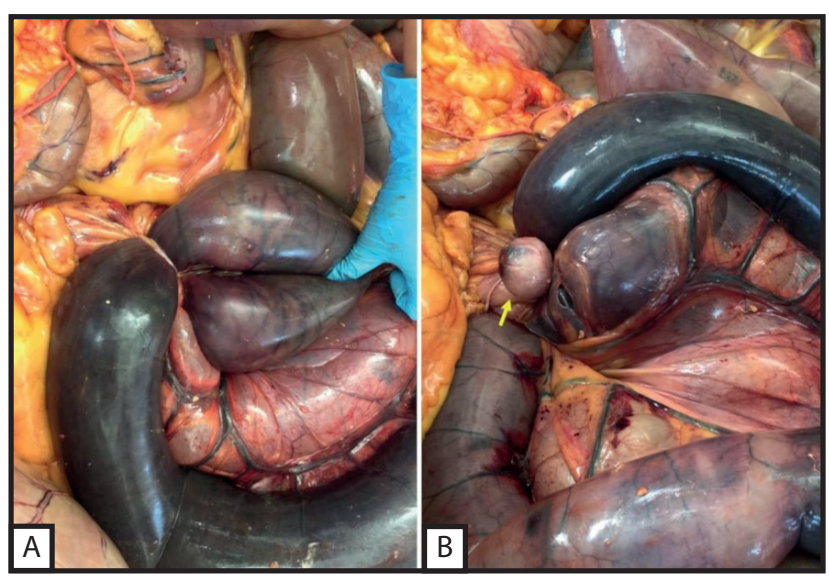

Figure 1. A- Pedunculated lipoma strangulating the affected portion of the small intestine. B- Lipoma adhered to the end of the peduncle that is strangulating part of the small intestine (yellow arrow). 


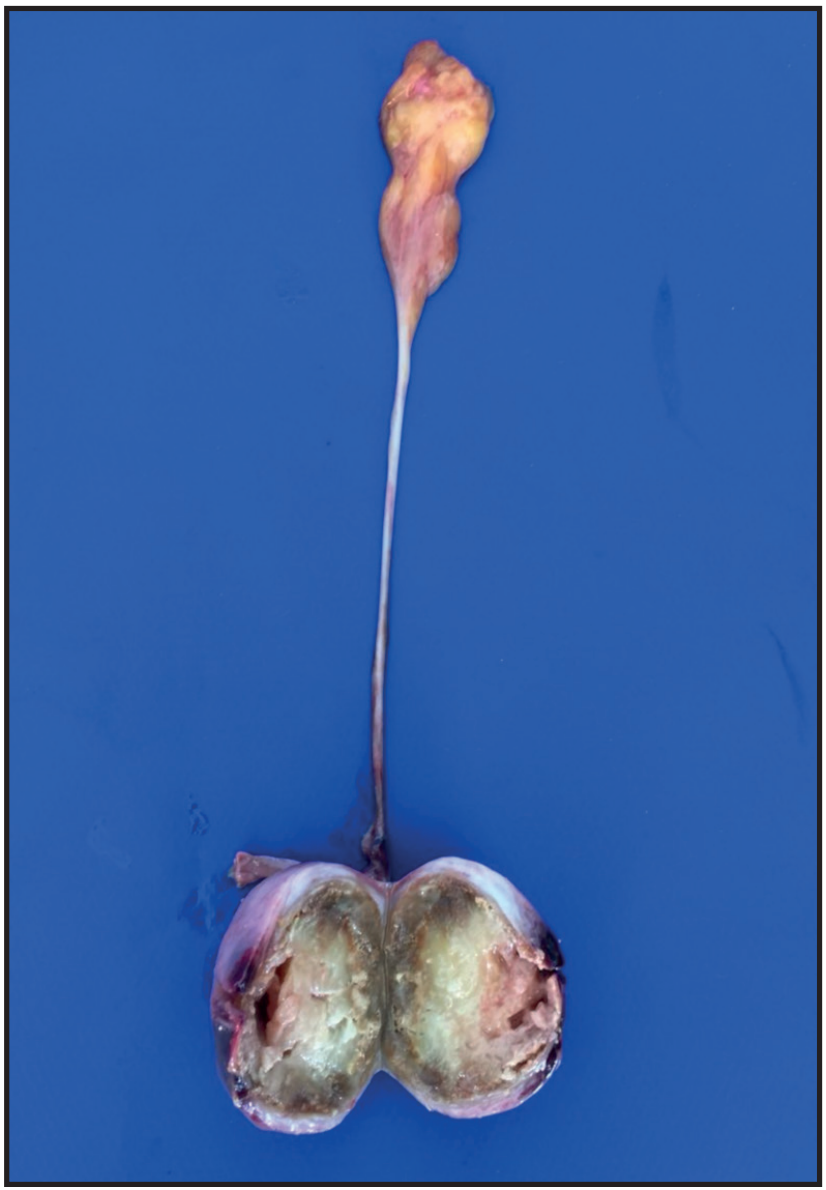

Figure 2. Roundish lipoma measuring $5 \mathrm{~cm}$ in diameter adhered to the end of a peduncle.

Although no scientific evidence of the association between obesity and pedunculated lipoma has been proven, Frank [6] has observed that pedunculated lipomas are more common in horses with metabolic alterations. Another author also found a higher frequency of this disease in horses presenting insulin resistance and diffuse pars intermedia hyperplasia [14]. The mare reported in this study had a high BCS, however no metabolic profile was performed.

The frequency of occurrence may vary according to breed and population studied. Horses considered of short stature $(\leq 150 \mathrm{~cm})$ are more predisposed when compared to jumping or race horses, probably due to the difference in lipid metabolism between these categories [5]. Athlete horses generally present an ideal body condition score, while animals intended to morphology competitions usually have a higher BCS. Therefore, some authors assumed that Criollo breed is potentially predisposed to develop metabolic disturbances considering the genetic basis of the breed and the tendency towards obesity $[13,15]$.
The estimated incidence of gastrointestinal neoplasias in horses are less than $0.1 \%$ and approximately $5 \%$ in horses with clinical signs of colic. Mesenteric lipomas are the most frequent neoplasia of the gastrointestinal tract of horses [11]. Elderly horses are at highest risk of developing it, mainly because lipomas are slow-growing neoplasms that require years to eventually become a problem, occurring usually in animals with a mean age of 17.6 years [11]. However, there are reports of younger animals affected by this disease $[5,11,17]$. Geldings appear to have a greater predisposition [5], but, other authors describe that females are more commonly affected $[4,18]$.

According to a study [3], pedunculated lipomas account for $18 \%$ of all cases of colic treated. The same author reported that $44 \%$ of these lesions are found in the small intestine while another authors reported an incidence varying from 89 to $93 \%$, with only $10 \%$ found in the small colon $[7,9,16]$.

The pedicle usually forms a loop around an intestinal portion and occasionally may involve two separate intestinal segments, and may complicate surgical treatment, as observed in the present case [2]. The author further describes that the degree of intestinal involvement is variable and depends on the degree of strangulation caused by the pedicle and the duration of the strangulation. In the reported patient, the large extent of compromised intestinal loop was probably due to the duration of the lesion and because more than one intestinal segment was strangled by the pedicle.

Blind resection of the pedicle is necessary if the affected intestinal segment is difficult to exteriorize, but this resection may cause rupture of the mesentery and hemorrhage, which may lead to death [7]. The extensive area of intestinal necrosis aggravated by the impossibility of externalization of the affected segment observed in our patient lead the decision to proceed with euthanasia during the procedure, since an extensive resection is indicative of a poor prognosis for the postoperative survival of the patient. The literature describes that postoperative patients with strangulating obstructions by pedunculated lipomas are three times more likely to suffer from adnamic ileus when compared to horses that presented other lesions $[2,7,8]$. In addition, when the patient is presented with previously established endotoxemia, they become more predisposed to mortality [5]. 
In conclusion, the mare of the present study had an advanced age and a high body condition score, which the authors' believe were two predisposing factors that increased the risk of it developing a mesenteric lipoma. Because of the mare's age and the extension of the segment affected by the lipoma, the prognosis for recovery was poor and lead to the final outcome. Considering that, further epidemiologic studies should be conducted to better understand this relation.

\section{MANUFACTURERS}

${ }^{1}$ Vansil Saúde Animal. Descalvado, SP, Brazil.

${ }^{2}$ Virbac do Brasil Indústria e Comércio Ltda. Hortolandia, SP, Brazil. ${ }^{3}$ Jofadel Indústria Farmacêutica. Varginha, MG, Brazil.

Acknowledgments. Our thanks to Ruth Patten for the English spelling check.

Declaration of interest. The authors report no conflicts of interest. The authors alone are responsible for the content and writing of the paper.

\section{REFERENCES}

1 Archer D.C. 2017. Diseases of the Small Intestine. In: Blikslager A.T., White N.A., Moore J.N. \& Mair T.S. (Eds). The Equine Acute Abdomen. 3rd edn. Hoboken: John Wiley \& Sons, pp.704-736.

2 Blikslager A.T. 2003. Strangulating Obstruction of the Small Intestine. In: Sprayberry K.A. \& Robinson N.E. (Eds). Current Therapy in Medicine Equine. 5th edn. St. Louis: Saunders Elsevier, pp.124-126.

3 Brosnahan M.M. \& Paradis M.R. 2003. Demographic and clinical characteristics of geriatric horses: 467 cases (1989-1999). Journal of the American Veterinary Medical Association. 223(1): 93-98.

4 Dart A.J., Snyder J.R., Pascoe J.R., Farver T.B. \& Galuppo L.D. 1992. Abnormal conditions of the equine descending (small) colon: 102 cases (1979-1989). Journal of the American Veterinary Medical Association. 200(7): 971-978.

5 Edwards G.B. \& Proudman C.J. 1994. An analysis of 75 cases of intestinal obstruction caused by pedunculated lipomas. Equine veterinary journal. 26(1): 18-21.

6 Frank N. 2009. Equine metabolic syndrome. Journal of Equine Veterinary Science. 29(5): 259-267.

7 Freeman D. 2009. Diseases of the Small Intestine. In: White N.A., Moore J.N. \& Mair T.S. (Eds). The Equine Acute Abdomen. 2nd edn. Jackson: Teton NewMedia, pp.593-616.

8 French N.P., Smith J., Edwards G.B. \& Proudman J. 2002. Equine surgical colic: risk factors for postoperative complications. Equine Veterinary Journal. 34(5): 444-449.

9 Garcia-seco E., Wilson D.A., Kramer J., Keegan K.G., Branson K.R., Johnson P.J. \& Tyler J.W. 2005. Prevalence and risk factors associated with outcome of surgical removal of pedunculated lipomas in horses: 102 cases (1987-2002). Journal of the American Veterinary Medical Association. 226(9): 1529-1537.

10 Henneke D.R., Poiter G.D., Kreider J.L. \& Yeates B.F. 1983. Relationship between condition score, physical measurements and body fat percentage in mares. Equine Veterinary Journal. 15(4): 371-372.

11 Hillyr M. 2002. Gastrointestinal Neoplasias. In: Mair T., Divers T.J. \& Ducharme N. (Eds). Manual of Equine Gastroenterology. Edinburgh: Saunders Elsevier, pp.334-338.

12 Jones S.L \& Smith B.P. 2014. Disease of the alimentary tract. In: Smith B.P. (Ed). Large Animal Internal Medicine. 4th end. St. Louis: Mosby Elsevier, pp.733-736.

13 Marchiori M.O., Kasinger S., Silva K.R., Souza L.S., Amaral L.A., Nogueira C.E.W. \& Roll V.F.B. 2015. Medidas comparativas do padrão morfométrico e perfil energético de éguas Crioulas no terço final da gestação, com diferentes escores corporais. Arquivo Brasileiro de Medicina Veterinária e Zootecnia. 67(3): 707-715. doi.org/10.1590/16784162-7705

14 Newkirk K.M., Chameroy K.A., Tadros E.M., Rohrbach B.W. \& Frank N. 2014. Pituitary Lesions, Obesity, and Mesenteric Lipomas in Insulin-Resistant Horses. Open Journal of Veterinary Medicine. 4: 190-196.

15 Paz C.F.R., Paganela J.C., Santos C.A., Nogueira C.E.W. \& Faleiros R.R. 2013. Relação entre obesidade, insulina plasmática e posicionamento da falange distal em equinos da raça Crioula. Arquivo Brasileiro de Medicina Veterinária e Zootecnia. 65(6): 1699-1705.

16 Rakestraw P.C. \& Hardy J. 2006. Large intestine. In: Auer J. \& Stick J.A. (Eds). Equine Surgery. 3rd edn. St. Louis: Saunders Elsevier, pp.436-478. 
R.P. Souza, L.A. Rafael, M.A. Mousquer, et. al. 2020. Small Intestine Strangulating Obstruction by Mesenteric Pedunculated Lipoma in a Criollo Mare. Acta Scientiae Veterinariae. 48(Suppl 1): 512.

17 Rosa G.S., Alonso J.M., Marsiglia M.F., Conceição M.L., De Paula T. V. Hussni C.A., Alves A.L.G., Rodrigues C.A. \& Watanabe M.J. 2017. Lipomas mesentéricos múltiplos em equino jovem: relato de caso. Revista Acadêmica: Ciência Animal. 15(Suppl 1): 305-306.

18 Shumacher J. 2002. Diseases of the small colon and rectum. In: Mair T., Divers T. \& Ducharme N. (Eds). Manual of Equine Gastroenterology. Edinburgh: Saunders Elsevier, pp.299-315. 